\title{
Niños y adolescentes trabajadores en las calles de Lima: vida cotidiana y estrategias familiares de supervivencia
}

Enfants et adolescents travailleurs dans les rues de Lima : vie quotidienne et stratégies familiales de survie

Working children and adolescents in the streets of Lima: daily live and family survival strategies

\section{Antonella Invernizzi}

\section{(2) OpenEdition}

Journals

Edición electrónica

URL: http://journals.openedition.org/bifea/4287

DOI: 10.4000/bifea.4287

ISSN: 2076-5827

\section{Editor}

Institut Français d'Études Andines

\section{Edición impresa}

Fecha de publicación: 1 diciembre 2013

Paginación: 505-523

ISSN: 0303-7495

Referencia electrónica

Antonella Invernizzi, « Niños y adolescentes trabajadores en las calles de Lima: vida cotidiana y estrategias familiares de supervivencia », Bulletin de I'Institut français d'études andines [En línea], 42 (3)। 2013, Publicado el 08 diciembre 2013, consultado el 05 noviembre 2020. URL : http:// journals.openedition.org/bifea/4287 ; DOI : https://doi.org/10.4000/bifea.4287

Les contenus du Bulletin de l'Institut français d'études andines sont mis à disposition selon les termes de la licence Creative Commons Attribution - Pas d'Utilisation Commerciale - Pas de Modification 4.0 International. 


\title{
Niños y adolescentes trabajadores en las calles de Lima: vida cotidiana y estrategias familiares de supervivencia
}

\author{
Antonella Invernizzi*
}

\begin{abstract}
Resumen
Este artículo muestra algunas de la facetas de la vida cotidiana de los niños y adolescentes que trabajan en la calle, y de sus familias. Aunque se refiere a una investigación realizada en Lima entre 1994 y 1999, no consiste en describir la realidad peruana de los años 1990 ni en presentar un análisis exhaustivo del trabajo infantil y de las políticas sociales que se han desarrollado hasta la actualidad. Se trata más bien de ilustrar un conjunto de enfoques que, a nivel microsocial, permiten comprender las prácticas cotidianas de los niños, niñas y adolescentes que trabajan en la calle. Para mostrar la importancia de los aspectos a la vez económicos, sociales, culturales y de identidad, se presentan datos procedentes de otros dos estudios cualitativos sobre el trabajo de los niños en Portugal y en Grecia. La hipótesis subyacente a este análisis es que una mejor comprensión de las prácticas cotidianas de los niños y de sus familias permite promover programas adaptados y, de hecho, más eficientes.
\end{abstract}

Palabras clave: infancia, trabajo, calle, familia, socialización, supervivencia, identidad, políticas sociales, Perú

\section{Enfants et adolescents travailleurs dans les rues de Lima : vie quotidienne et stratégies familiales de survie}

\section{Résumé}

Ce texte montre quelques unes des facettes de la vie quotidienne des enfants et adolescents qui travaillent dans la rue, et de leurs familles. Bien qu'il se réfère à une recherche réalisée à Lima entre 1994 et 1999, il ne vise pas à décrire la réalité péruvienne des années 1990, ni à présenter une analyse exhaustive du travail des enfants et des politiques sociales qui ont été mis en place jusqu'à

* Investigadora independiente y consultora, Francia, colaboradora científica Universidad de Fribourg, Suiza. E-mail: anto_invernizzi@yahoo.com 
aujourd'hui. Il s'agit plutôt d'illustrer un ensemble d'éclairages qui, au niveau microsocial, permettent de comprendre les pratiques quotidiennes des enfants et adolescents, filles et garçons, qui travaillent dans la rue. Afin de montrer l'importance des aspects à la fois économiques, sociaux, culturels et identitaires, des données provenant de deux autres études qualitatives sur le travail des enfants au Portugal et en Grèce sont présentées. L'hypothèse sous-jacente à cette analyse est qu'une meilleure connaissance des pratiques quotidiennes des enfants et de leurs familles permet de promouvoir des programmes adaptés et de fait plus efficaces.

Mots-clés: enfance, travail, rue, famille, socialisation, survie, identité, politiques sociales, Pérou

\title{
Working children and adolescents in the streets of Lima: daily live and family survival strategies
}

\begin{abstract}
This paper examines some facets of the daily life of children and adolescents street workers, and their families. Although it refers to a research carried out in Lima between 1994 and 1999, it is not to describe the Peruvian reality of the 1990, or to present a comprehensive analysis of child labor and social policies that have been implemented until today. Its objective is rather to illustrate a set of approaches that, at the micro level, allow to understand everyday practices of children and adolescents street workers. In order to show the significance of economic, social, cultural and identity dimensions, material from two others qualitative studies on children's work in Portugal and in Greece are presented. The underlying assumption of this analysis is that a better understanding of children's everyday practices and their families facilitates appropriate and more efficient programs.
\end{abstract}

Keywords: childhood, work, street, family, socialization, survival, identity, social policies, Peru

\section{INTRODUCCIÓN}

Esta presentación se refiere a un conjunto de investigaciones realizadas con niños y adolescentes ${ }^{1}$ trabajadores con un peculiar énfasis en el trabajo en las calles de Lima (Invernizzi, 2001; 2003a). El trabajo de campo de este estudio se realizó durante largos periodos entre 1994 y 1997 utilizando un enfoque etnográfico y métodos cualitativos: observación semiparticipante, entrevistas (a los padres, niños, niñas y adolescentes), discusiones informales y fotografías. La referencia para esa metodología se encuentra en los trabajos de Riccardo Lucchini (1993; 1996) sobre los niños en situación de calle y otros autores, que atribuyen mucha

1 El término «niños y adolescentes», en este texto, se refiere a las personas menores de 18 años, conforme a las definiciones de los instrumentos internacionales de los derechos del niño. La referencia a la adolescencia pretende evitar la confusión que, como lo subraya Cantwell (2011), se genera con una definición larga de la niñez que no da cuenta de las diferentes edades de los niños. 
importancia al triangular las informaciones y los informantes, y en compartir aspectos de la vida cotidiana durante largos periodos. La postura teórica asociada a estos estudios es la del niño como actor social y sujeto con un interés central en conocer la forma como el o ella interpreta su propia situación, sus motivaciones, experiencias y estrategias. Este enfoque fue desarrollado también por la «nueva sociología de la infancia» en Gran Bretaña, y particularmente en la publicación de James y Prout (1990) que pone énfasis no solo en una visión del niño como actor social sino también en la noción de que la misma infancia es una construcción social; la imagen y la experiencia del niño se relacionan con el contexto social, económico y cultural donde vive. La infancia en ese enfoque es inseparable de las dimensiones de género, etnicidad, capacidad-discapacidad o condición económica, lo que había sido analizado anteriormente por Ennew (1986) en relación a las niñas trabajadoras en el Perú.

Mas allá de lo que preconiza la nueva sociología de la infancia británica, el estudio en Lima no se concentró exclusivamente en los niños y adolescentes trabajadores sino también en sus familias y su organización, es decir en su contexto social y cultural más amplio. La misma observación de la vida cotidiana de una parte importante de los niños y niñas que se encontraban trabajando en el centro de Lima mostraba que una mayoría tenía una organización del trabajo de tipo familiar. Las actividades cotidianas del niño actor social, entonces, debían ser estudiadas en relación a las particulares estructuras y exigencias en su medio de vida. Se atribuyó un interés particular a las condiciones de las mujeres madres y jefes de hogar. En la venta de calle en el centro de Lima, muchas familias tenían un tipo de estructura familiar monoparental y algunas madres indicaban el abandono del hombre como el principal motivo para desarrollar una actividad económica en la calle con sus hijos. En ese espacio, obraba al inicio del trabajo de campo la organización gubernamental INABIF (Instituto Nacional del Bienestar Familiar) que realizaba un trabajo de calle para apoyar a las familias y a los niños. Los discursos de las madres al respeto de los problemas económicos llevaron a introducir en ese contexto una investigación/ acción que tomó la forma de créditos a madres de niños trabajadores así como a dos adolescentes. Un segundo trabajo de campo se concentró en un mercado fuera de Lima donde un grupo de adolescentes lustrabotas trabajaba y se encontraba en un proceso de organización en el marco de las actividades de PRONATS2.

Las informaciones recogidas en Lima hace más de 15 años perdieron su validez para describir la realidad actual de los niños trabajadores, por los muchos cambios que han ocurrido en términos económicos, políticos, sociales y culturales, los cuales han modificado de forma significativa la situación de los niños en el Perú. El propósito de este texto no consiste, por lo tanto, en describir una realidad sino en ilustrar enfoques y conceptos utilizados para el análisis. El postulado

2 EI INABIF y PRONATS, las dos organizaciones que colaboraron durante la encuesta de campo, tienen diferentes posiciones y metodologías en relación al trabajo infantil (Invernizzi, 2003b). 
principal es que en las miradas cruzadas producidas por diferentes enfoques, y aquí solamente algunas pudieron ser expuestas, se encuentra la riqueza necesaria para pensar intervenciones y políticas sociales a favor de los niños y niñas trabajadores. Este artículo no desarrolla específicamente un análisis de las políticas sociales, posturas e intervenciones que existían y existen en el Perú, así como su amplia contribución en la investigación y en la conceptualización del trabajo de los niños y niñas. Más bien se propone presentar algunos enfoques que se pueden aplicar a realidades muy diferentes a la del trabajo en la calle en el Perú, como por ejemplo el trabajo en el medio rural en Portugal y el trabajo infantil en las calles de Europa por los niños migrantes provenientes del Este de este continente.

Quisiera en primer lugar presentar una caracterización del trabajo familiar en la calle como una de las modalidades de trabajo de los niños. En segundo lugar, se especificará una conceptualización del trabajo de los niños y adolescentes alrededor de cuatro dimensiones (supervivencia, socialización, autonomía y explotación). Esta surgió de un análisis comparativo entre las informaciones de la encuesta en Lima y las de un estudio realizado en zonas rurales en el sur de Portugal entre 2001 y 2002 (Invernizzi, 2005; Invernizzi \& Tomé, 2007). Finalmente, se explicará la noción de carrera referente al niño trabajador en la calle.

\section{LA ORGANIZACIÓN DE LAS FAMILIAS DE NIÑOS TRABAJADORES EN EL CENTRO DE LIMA EN LOS AÑOS 1990}

Durante el estudio en Lima, el testimonio de las madres de niños trabajadores en el centro de la ciudad se enfocaba en la omnipresencia de la pobreza que parecía dictar todas sus rutinas cotidianas. Por cierto, la crisis económica y las medidas de ajuste estructural al inicio de los años 1990 generaron un empobrecimiento general y dejaron muchos hogares sin otros recursos más que la mendicidad o la venta de golosinas en la calle (Alarcón, 1991). Mas allá de la pobreza, la forma de organización de las actividades cotidianas parecía importante. Muchas preguntas surgían de las diferencias entre una familia ${ }^{3}$ y otra: ¿por qué en algunas familias la organización permitía alcanzar las necesidades más básicas y también a veces la escolarización de los niños y originar en ellos una relativa satisfacción en el trabajo cuando en otras se encontraban conflictos e insatisfacción?

Una estrategia para explorar esta diversidad fue la de establecer un pequeño programa de microcréditos o concesión, sugerido a algunas familias. Esto se motivaba por la necesidad de dar una respuesta — aunque muy limitada - a

3 La noción de familia se utiliza aquí en un sentido amplio y no se refiere a la familia nuclear. Se trata de familias con estructuras diversas y que se modifican en el tiempo (Invernizzi, 2001). La noción de familia, y no la de hogar, es la que refleja mejor el discurso de los informantes. El concepto de hogar se utiliza entonces en referencia a la literatura y a los aspectos más técnicos de la organización del trabajo. 
los pedidos de las mujeres en relación a los urgentes problemas económicos4. En primer lugar, fueron las mismas representaciones alrededor de la familia, del trabajo y de la infancia así como las ligadas a la vida cotidiana que llamaron la atención. Estas eran variadas y parecían corresponder con modelos diferentes. Dos tipos ideales, en la perspectiva de Max Weber, fueron construidos para dar cuenta de esta diversidad: un modelo «urbano» y uno «andino» (Invernizzi, 2001; 2003a), como forma algo arcaica y simplificadora de demostrar la construcción social y cultural de la infancia (véase el cuadro 1). Por lo tanto, hay que subrayar que los tipos ideales tal como los define Max Weber (1982) acentúan características para demostrar un argumento pero no reflejan absolutamente la realidad. En ese caso, algunas familias se acercaban más bien a las características de uno o del otro tipo pero muchas presentaban uno u otro sin corresponder enteramente con un modelo determinado.

Las referencias a estos modelos pueden encontrarse en la literatura que describe el modelo urbano machista de la familia de clase media de los años 1970 (Ruiz Bravo, 1996; Fuller, 1997) y las referencias al Ilamado «modelo andino» se encuentran en los trabajos de investigadores en la regiones rurales o testimonios de profesionales así como en estudios de migrantes en Lima (Ortiz Rascaniere, 1994; Portugal Catacora, 1988; Lobo, 1984; Ennew, 1986).

De forma evidente, la limitación importante de esta manera de conceptualizar las imágenes y representaciones de los actores se enfrenta con el riesgo de encerrarlas en «tradiciones» o en conceptualizaciones, sin considerar cómo la forma de ver el mundo cambia con la experiencia y es en parte subjetiva e individual. A pesar de eso, ignorar la diversidad y la construcción social de la familia, del trabajo y de la infancia conduce a individualizar los problemas de comunidades o categorías enteras, en un modelo de tipo psicológico. Eso también lleva a limitaciones importantes. Como veremos más adelante, las maneras de pensar el rol de la mujer y el de los niños tienen una influencia importante sobre la organización de la vida cotidiana.

Un segundo resultado del análisis de las informaciones producidas a través de los pequeños créditos fue precisamente una esquematización de la organización familiar como un sistema multidimensional con elementos de naturaleza económica, de identidad social y familiar, subrayando así cómo cada una de las dimensiones influencia a la otra (Invernizzi, 2001).

4 En un primer momento, no se trató tanto de promover un proyecto viable de ayuda económica sino de comprender los eventos de la vida cotidiana y las dificultades de estas familias. Una docena de madres y dos adolescentes recibieron créditos para ampliar un proyecto. La selección se operó intentando incluir situaciones diferentes y familias en las cuales niños y adultos expresaban una satisfacción relativa al respeto de la organización familiar así como familias con relaciones conflictivas. El análisis presentado abajo es el resultado de la comparación de estas organizaciones y la identificación de elementos, tales como el género, la representación del trabajo y de la infancia, de la carrera, etc. En un segundo momento, la responsabilidad de los créditos fue atribuida a una de las participantes con el objetivo de mantener el sistema de créditos activos después del trabajo de campo, lo que se logró durante unos 18 meses. 
Cuadro 1 - Imágenes de género, familia, trabajo e infancia en los modelos urbano y rural

\begin{tabular}{|c|c|c|}
\hline & Modelo urbano & Modelo rural \\
\hline $\begin{array}{l}\text { Identidad y roles } \\
\text { de género en la } \\
\text { familia }\end{array}$ & $\begin{array}{l}\text { División rígida del trabajo entre hombres y } \\
\text { mujeres: } \\
\text { - Idealmente empleo del hombre jefe } \\
\text { de hogar. Separación clara entre esfera } \\
\text { doméstica y espera profesional. } \\
\text { - La mujer debe idealmente ocupar el } \\
\text { espacio doméstico y se encarga de las tareas } \\
\text { domésticas y de los niños. } \\
\text { - La presencia de la mujer en el hogar es una } \\
\text { marca de éxito socioeconómico. }\end{array}$ & $\begin{array}{l}\text { División del trabajo flexible: } \\
\text { - Trabajo en la agricultura y trabajo informal. } \\
\text { - Organización del trabajo alrededor de la } \\
\text { familia. } \\
\text { - La mujer participa en la producción aunque } \\
\text { queda asociada al mundo doméstico. }\end{array}$ \\
\hline $\begin{array}{l}\text { Creación de la } \\
\text { familia e imagen } \\
\text { de la sexualidad }\end{array}$ & $\begin{array}{l}\text { Doble moral sexual «machista»: } \\
\text { - Control sobre las mujeres del hogar. } \\
\text { Importancia de la virginidad. Matrimonio } \\
\text { como espacio legítimo de la sexualidad y } \\
\text { fecundidad. } \\
\text { - La definición de la masculinidad está } \\
\text { asociada a relaciones sexuales con varias } \\
\text { mujeres. }\end{array}$ & $\begin{array}{l}\text { - Ausencia de una condena moral del embarazo } \\
\text { antes del casamiento. La preocupación es de } \\
\text { tipo pragmático. }\end{array}$ \\
\hline $\begin{array}{l}\text { Imagen del trabajo } \\
\text { y de la calle }\end{array}$ & $\begin{array}{l}\text { - Para el hombre jefe de hogar, el trabajo } \\
\text { consiste idealmente en un empleo } \\
\text { asalariado que permite la subsistencia de } \\
\text { la familia. } \\
\text { - La calle es un espacio de socialización para } \\
\text { el varón que prueba su masculinidad fuera } \\
\text { de la espera doméstica. } \\
\text { - La calle no es un espacio de trabajo y se } \\
\text { opone a la vida familiar. } \\
\text { - La niña es excluida de la calle que representa } \\
\text { una «jungla» hecha de arbitrariedad, } \\
\text { amoralidad y sexualidad inapropiada. }\end{array}$ & $\begin{array}{l}\text { - Organización familiar del trabajo. } \\
\text { - El trabajo es un deber moral de cada miembro } \\
\text { de la familia y la comunidad. } \\
\text { - Las contribuciones de cada uno son } \\
\text { diferenciadas en relación a sus capacidades. } \\
\text { - La calle es un espacio aceptable para una } \\
\text { variedad de actividades económicas y } \\
\text { familiares. } \\
\text { - La diversificación de las actividades (y no } \\
\text { la especialización) dicta la organización del } \\
\text { trabajo. } \\
\text { - La calle, cuando puede ser ocupada de forma } \\
\text { estable se transforma en un espacio similar a un } \\
\text { mercado. } \\
\text { - Las transacciones ligadas al trabajo se } \\
\text { desarrollan alrededor de vínculos familiares, } \\
\text { entre vecinos, compadres, etc. Incluyen } \\
\text { prácticas de cooperación y solidaridad y no } \\
\text { solamente de concurrencia. }\end{array}$ \\
\hline El niño y el trabajo & $\begin{array}{l}\text { - Se excluye la participación del niño en el } \\
\text { mundo del trabajo. } \\
\text { - La escolaridad y el juego y, para el varón, } \\
\text { la sociabilidad con otro niños son sus } \\
\text { principales actividades. } \\
\text { - La educación está centrada principalmente } \\
\text { en los adultos. }\end{array}$ & $\begin{array}{l}\text { La organización de la familia andina rural integra } \\
\text { al niño en la producción. La concepción del niño } \\
\text { como trabajador está asociada a prácticas de } \\
\text { socialización: } \\
\text { - Sus responsabilidades aumentan al mismo } \\
\text { tiempo que su autonomía en la gestión del } \\
\text { trabajo y de los ingresos. } \\
\text { - El niño organiza desde temprano sus ingresos. } \\
\text { - El juego, la experimentación y la exploración } \\
\text { tienen un papel central en el aprendizaje de las } \\
\text { actividades agrícolas. } \\
\text { - El niño goza de una gran autonomía espacial } \\
\text { que asocia trabajo, juego y exploración. }\end{array}$ \\
\hline
\end{tabular}


El análisis intentó responder a la pregunta «ipor qué los adultos y niños hacen lo que hacen y por qué lo hacen de la forma como lo hacen?». Una variedad de elementos explican sus actividades cotidianas y la diferencia de su importancia en cada hogar. Estos elementos están presentados en la figura 1. Las dimensiones 2 y 3 relacionadas a la división del trabajo entre hombres y mujeres, y entre niños y adultos ya fueron presentadas. Las cuestiones simbólicas o de identidad (4, 5 y 8, es decir cómo los actores piensan que las cosas deberían desarrollarse en la familia) se refieren a lo que mencionábamos anteriormente; el hecho de que adultos y niños, como actores sociales, tienen una forma de representarse el trabajo, la familia o la infancia pero ellos reinterpretan esas ideas para apropiarlas y modificarlas según su propia experiencia. Por ejemplo, una mujer tenía que volver a la casa con sus hijos cada día para prepararle la comida a su esposo en el momento del día donde el negocio era más rentable. Eso ocurría a pesar de que la familia tenía una gran necesidad de dinero. Para esta mujer, el rol de trabajadora era secundario al de esposa y su organización cotidiana estaba marcada por una visión de la familia donde el hombre jefe de hogar era el trabajador principal, si no el único trabajador en la familia. Al contrario, otras mujeres indicaban no querer tener una relación de pareja para lograr suficiente autonomía y asegurar la supervivencia de su familia o rechazar una organización tradicional de la vida cotidiana alrededor de necesidades simbólicas de la pareja (Invernizzi, 2001).

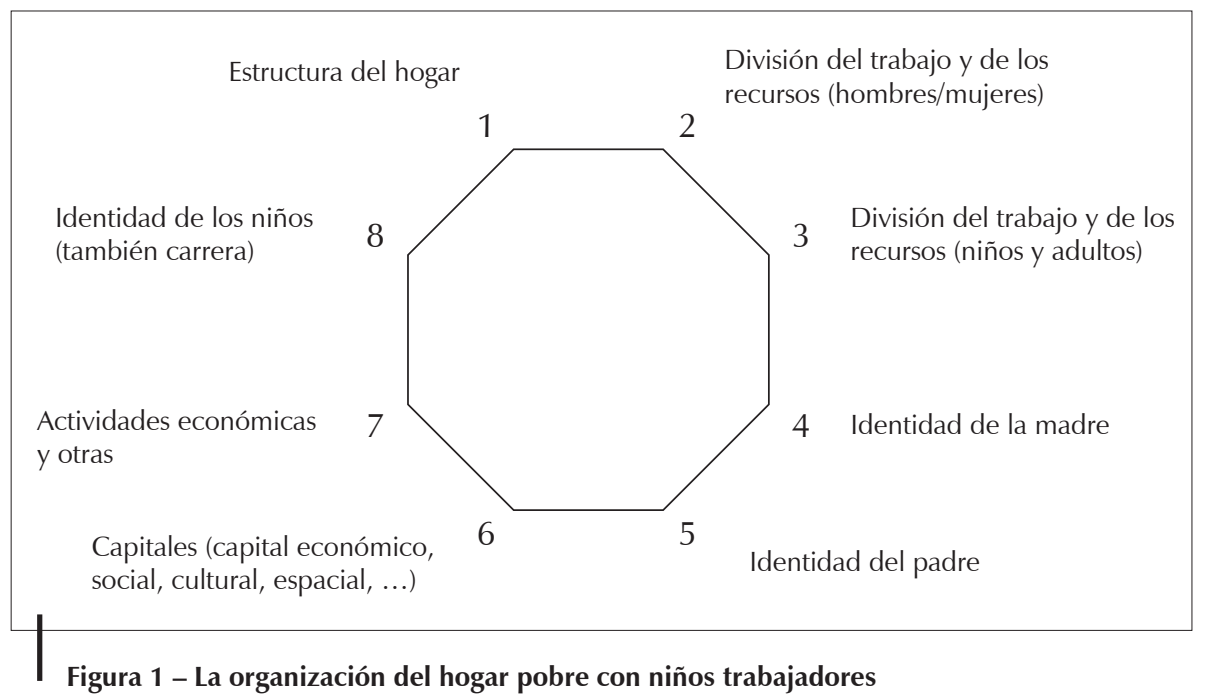

Algunos niños parecían gozar de una gran confianza y autonomía de parte de los padres. Otros estaban sometidos al control y a una protección que podrían considerarse excesivos en lo que reducían la capacidad del niño a aprender, utilizar sus competencias o simplemente jugar y explorar la ciudad. Como veremos más allá en relación a la socialización y la carrera, los niños tienen sus propias visiones del trabajo y sus intereses evolucionan con la experiencia. Los 
conflictos entre niños trabajadores y padres, a veces importantes y violentos, no se pueden entender sin referencia a las organizaciones familiares o a los intereses propios de los niños.

Los elementos simbólicos y ligados a la identidad, tal como las imágenes de la mujer, del trabajo o de la familia desarrollados anteriormente, no pueden explicar solos la forma cómo el trabajo de la familia y de los niños se organiza en la vida cotidiana. La estructura del hogar, por ejemplo, juega un rol central en la explicación que los actores dan. El abandono del padre, la enfermedad o los accidentes en muchos casos estaban relacionados con la salida a la calle para generar provechos de cualquier forma. En muchos casos, la estructura del hogar es cambiante y cada cambio exige un ajuste en la organización. La estructura del hogar puede igualmente presentar recursos importantes. La presencia de una abuela o de una hija adulta o adolescente permite, por ejemplo, a una madre dejar a los niños más pequeños en la casa y desarrollar una actividad económica más lucrativa. La mujer que no tiene este recurso tiene que buscar espacios seguros para los niños pequeños en vez de buscar los espacios que generan más ventas y beneficios.

Los capitales que la familia puede o no tener también deben ser considerados. La importancia del capital económico es evidente. Algunos negocios ambulantes generan beneficios importantes y los niños que trabajan en esos gozan muchas veces de mejores condiciones de vida y en muchos casos, de presiones reducidas para generar créditos. Además de las diferencias económicas, hay que subrayar cómo el capital social y cultural (Bourdieu, 1990) —al lado de una ocupación estable de un espacio de venta - son importantes para organizar el trabajo de la familia y de los niños. Las redes informales de cooperación entre vendedores informales así como las redes entre vecinos son indispensables. Estas permiten el intercambio de informaciones y servicios así como el soporte para la supervisión de los niños. Así, un niño de 8 años que todavía no sabía abrir las botellas de gaseosa podía venderlas en ausencia de la madre porque una vecina iba a abrirlas por él y, por lo tanto, ayudaba al niño en otros asuntos si era necesario. El capital cultural, es decir las informaciones y competencias necesarias para el negocio en la calle son también importantes. Para los ambulantes, se trata de saber qué vender, cómo y dónde obtener el soporte, cuáles son los peligros para el vendedor, para los niños y la forma cómo enfrentarlos. Todo eso, que se verá posteriormente, es parte de la socialización de los niños y adolescentes trabajadores.

Estas dimensiones necesitan una consideración central en las intervenciones en la medida en que la sola dimensión económica no permite apreciar las responsabilidades de estas mujeres (y muy raramente de los hombres) cuando asumen responsabilidades simultáneas a nivel familiar y laboral. Las madres entrevistadas durante la investigación se encontraban estigmatizadas como trabajadoras «poco productivas» y como madres «poco protectoras» (Invernizzi, 2003a; 2003b). Al contrario, muchos son los esfuerzos y las estrategias desarrolladas para conciliar estos aspectos, como lo explica bien el caso de Antonia, quien a 
pesar de tener un diploma como profesional, prefiere la venta en la calle en el centro de Lima:

Investigador: ¿Pero a usted no le atrae, por ejemplo, el trabajar para alguien no? [...]. De repente en una fábrica...

Antonia: Pero mientras está un hijo, ¿cómo? Lo voy a tener abandonado.

Investigador: ¿Es para su hijo principalmente?

Antonia: Sí pues. Por eso lo que trabaja en la calle, porque yo, mire, de meterme a una confección, yo me meto ahorita, porque yo sé coser, yo sé remallar [...]. Entonces mejor como ambulante, hasta cuando sea más grandecito.

Investigador: Y en la casa, ¿no hay forma [de coser]?

Antonia: Yo de coser, ¿quién me pagaría? La gente pobre está allá. Por qué digo... mire, de ocho añitos lo voy a dejar [a mi hijo] solo: fácil, pa' que agarre cualquier vicio, se junta con malos amigos y ¿cómo lo voy a controlar si yo estoy trabajando? No voy a poder [...]. Sí, yo prefiero ambulante, aunque sea con golosinas. Claro, no llueve [el dinero], pero todos los días gotea pue', siquiera pa' llevar para la olla, aunque no sea grande ino?, pero todos los días tiene que haber para la olla...

Esa realidad también se aplica a una parte de las niñas o los niños quienes, como las madres, van a alternar entre tareas domésticas, cuidados a niños más pequeños y actividades económicas así como ir a la escuela. Por ejemplo, es frecuente que un hermano/a mayor o un primo/a introduzca a un niño en el trabajo de calle. Hay que subrayar que ese tipo de análisis se aplica más allá del contexto de trabajo de calle en Lima. Un estudio reciente sobre las prácticas de mendicidad y pequeños trabajos informales de mujeres migrantes con niños de las comunidades romaní de los países del este de Europa muestra las mismas dificultades en términos de estigmatización de las madres (Invernizzi, 2011). El estudio muestra cómo la mirada dominante ve el trabajo en la calle y la mendicidad como un problema social y el niño trabajador en la calle como un niño explotado. La tendencia dominante es de considerar a la madre como responsable de las condiciones laborales de sus hijos e hijas y de la falta de protección que ellos sufren. Raramente se menciona que se trata de madres jefes de hogar y que una migración de toda la familia, o de parte de ella, es una opción más apropiada que la de dejar a los niños en el país de origen sin soporte alguno. El trabajo o la mendicidad que la madre toma a cargo también se suele examinar como una forma de marginalidad y asociado a la cultura romaní. La investigación mostró que algunas de esas madres habían sido víctimas de trata de seres humanos y otras se encontraron en la calle porque el trabajo que se le había prometido cuando migraron no se había materializado. No tenían entonces ninguna otra opción que vender pequeños objetos o pedir dinero con sus hijos para cobrar los gastos de transporte hacia su domicilio e intentar conciliar las necesidades económicas y el cuidado de los niños de la mejor manera. A pesar de las formas de opresión e precariedad en que ellas mismas se 
encuentran, la mirada dominante de las autoridades y organizaciones las definía como responsables de la situación y de las dificultades de los niños. Como en el estudio de niños trabajadores en Lima, eso subraya la necesidad de desarrollar un análisis de género para entender la realidad y dificultades de los niños y resituarla en la de las familias, con justa consideración para el trabajo productivo y las tareas reproductivas.

\section{EL TRABAJO DE LOS NIÑOS Y ADOLESCENTES COMO ESTRATEGIA DE SUPERVIVENCIA, SOCIALIZACIÓN, PRÁCTICA DE AUTONOMÍA, AUTODETERMINACIÓN Y EXPERIENCIA DE EXPLOTACIÓN}

Otro eje de análisis consiste en ubicar las motivaciones de los niños, niñas y adolescentes, y de los adultos alrededor de ellos, en un marco teórico suficientemente largo para no invalidar sus experiencias. El trabajo como se realiza en la vida cotidiana de los niños y niñas presenta características que simultáneamente se interpretan en términos de supervivencia, socialización, autodeterminación y explotación. La intensidad de cada dimensión varía según el tipo de trabajo, el contexto y las condiciones pero también según aspectos más subjetivos como la identidad del niño.

Debido a las difíciles condiciones económicas, la experiencia de los niños trabajadores de la calle en Lima durante los años 1990 está hecha de presiones muy fuertes en relación con la supervivencia. Entonces, la cuestión de la socialización no era siempre explícita en los discursos de los informantes en la medida en que las referencias a la supervivencia eran predominantes. Sin embargo, los aspectos ligados a la transmisión de valores y prácticas así como de la reinterpretación de ellas por los niños y niñas eran significativos. Eso se puede entender a través del contenido de los tipos ideales detallados arriba, que incluyen valores y prácticas transmitidas a los niños y niñas y, como se verá más adelante, reinterpretadas por ellos. La noción basada en el hecho de que cada miembro de la familia tiene que contribuir al bienestar de la familia, por ejemplo, que caracteriza la división del trabajo en la tradición andina, está ligada a la valoración del trabajo así como a una respuesta a las necesidades económicas.

El caso de Elena y su hija Nelly ilustra estos aspectos y prácticas que más bien se acercan al modelo andino de la familia y del trabajo. Antes de Navidad, le atribuimos a Nelly un préstamo de 20 dólares que programó utilizar para comprar y revender pequeños fuegos artificiales. Además de los 20 dólares prestados, ella recurrió a sus propios ahorros y a una contribución de su madre, Ilegando a 26 dólares. La venta de los fuegos de artificios produjo unos 40 dólares. Su madre la asesoró pero la gestión del proyecto estaba en las manos de Nelly. Después de Navidad Nelly utilizó nuevamente 26 dólares para comprar fuegos artificiales, consiguiendo los mismos beneficios. Restituyó los 20 dólares del préstamo y, con las ganancias, se compró ropa y zapatos para ella misma, sus hermanas y su 
abuela. A pesar de que la madre en esta oportunidad le pidió una contribución a Nelly para apoyar a otros miembros de la familia, la forma que esa contribución tomó fue una fuente de gratificación. Esta fue reconocida y valorada mediante la compra de ropa y regalos que quedaban visible después de las fiestas. A pesar de la gran necesidad económica que hizo el trabajo de los niños indispensable para la supervivencia, esta forma de utilizar los provechos de los niños mostró marcas culturales y fue parte de una forma de socialización que valora el mismo trabajo. La regla en esta familia era que cada niño y niña conservara una parte de sus ganancias en un «bocal» y lo ahorrara para gastos personales importantes. Si una contribución para el hogar es necesaria, esta tiene que ser justificada y valorada. La «tutela» a un hermano menor es una práctica frecuente en ese medio. Estas prácticas se oponen a las de organizaciones familiares donde el adulto maneja todas las ganancias de los niños como parte del presupuesto de la familia. El niño es considerado como «incapaz» de manejar dinero lo que, en las familias observadas, ha sido fuente de menos autonomía y mayores conflictos (Invernizzi, 2001).

La importancia de la socialización aparece en una investigación realizada en Portugal (Invernizzi, 2005; Invernizzi \& Tomé, 2007). A pesar de los niveles de pobreza existentes en zonas rurales, la función de supervivencia en relación al trabajo de los niños suele ser menos significativa en términos económicos para una parte importante de los niños y adolescentes encontrados. Pero los aspectos ligados a la ayuda a la familia y a la socialización han aparecido como centrales en los discursos de muchos adolescentes y adultos: el trabajo, ya sea en la agricultura, el pastoreo, los restaurantes o negocios, permite al niño y a la niña «aprender el valor de las cosas», descubrir actividades y talentos. Es entonces valorado como una actividad paralela a la escuela y, si el fracaso escolar ocurre, como inserción y socialización alternativa.

La explotación y el abuso son otras dimensiones del trabajo infantil. En Portugal, las definiciones de abuso estaban, en algunos casos, ligadas a la socialización, pues si el trabajo es visto para muchos informantes como una forma de aprender, algunos declararon que el trabajo no les permitía aprender un oficio y era una forma de explotación. En Lima, una definición interesante observada fue justamente la de Elena, vendedora ambulante en el centro de Lima, madre de Nelly (véase líneas anteriores) y cuatro niños más. Ella indicaba que el trabajo del niño «debe mejorar sus condiciones de vida». Ella observaba a otros niños y adolescentes que andaban sucios y que cada día llevaban todo el dinero a sus padres, los cuales no trabajaban. Otros aspectos relacionados a la explotación y al abuso se refieren a lo que niños y adultos deben pagar a intermediarios, guachimán o policías para poder trabajar en la calle o para guardar el material de trabajo durante la noche. Esos gastos, a veces, no tienen ninguna relación con el servicio ofrecido.

La cuestión del género, como podemos imaginar, es importante en relación con el tema del abuso y de la explotación. Las visiones de la calle, de la mujer y de la sexualidad influencian en lo que un observador verá como trabajo peligroso para la niña y una forma de abuso. Si se relaciona a un modelo de tipo urbano y patriarcal 
de la familia presentada anteriormente, la presencia de la niña en la calle es, en sí mismo, una situación de peligro. En las calles de Lima se podían observar otras visiones de lo que es abuso y riesgo. Algunas familias promovían una organización de tipo familiar del comercio de calle y no consideraban sistemáticamente la calle como una fuente de peligro y promovían una relativa protección a las niñas que no limitaba su autonomía más de lo necesario. Un análisis concreto de los riesgos, y no un discurso moral sobre la calle, era lo que dictaba las prácticas cotidianas de los padres y de los niños.

La autodeterminación del niño y de la niña a través del trabajo —entendida como una mayor autonomía e impacto sobre su vida y su entorno- es otro aspecto importante. De forma general, hay diferencias importantes entre lo que se observó en Lima y las informaciones recogidas en el sur de Portugal. En Lima, los niveles de autonomía de los niños trabajadores son mucho más significativos. El trabajo es para algunos niños y adolescentes una fuente importante de autodeterminación que permite luchar contra la pobreza y mantener proyectos a pesar de las dificultades. Es probable que en todas partes del mundo algunos niños logren sobrevivir, ayudar a la familia y/o ir a la escuela porque trabajan. Lo que las informaciones de la investigación en Lima subrayan es cómo estos aspectos están valorados en algunas familias, lo que se asocia a una noción de «progreso» a través del esfuerzo cotidiano. Como lo indican dos niños lustrabotas a quienes les preguntamos qué le dirían a los niños del Perú:

Nelson: Hasta que todos los niños que estén por allí... o sea que trabajen...

Edwin: Nosotros no tenemos que estar andando, robando, en vez que roben deben trabajar, eso les decimos a todos que estén andando allí, pidiendo plata. Puedes, puedes pedir plata y comprarte una bolsita de caramelos para vender, como muchos de mis amigos lo hacen... [eso] sí.

Investigador: Pero así hay que vender, ¿no?

Nelson: Así, hay que trabajar o sea nunca, nunca...

Edwin: Y algún día ser grandes progresistas...

Nelson: Y estudiar!

Edwin: Progresistas y estudiar también! Estudiar es la mejor arma para todos los niños del Perú y todo el mundo...

Así, la autonomía de algunos niños está valorada positivamente y promovida al lado del juego y la experimentación durante la socialización. El niño o la niña «tiene derecho» a decidir en asuntos que otros grupos y otras sociedades reservan a los adultos. El comercio independiente y la gestión del dinero es un ejemplo típico de esa autonomía donde la socialización promueve desde temprana edad las competencias necesarias para un pequeño comercio individual, tal vez al lado de la «ayuda» en el negocio de los padres. En las regiones rurales al sur de Portugal, no se encontraron tales niveles de autonomía entre los niños trabajadores. Lo que se encontró fue una representación de la familia como unidad económica de trabajo y un énfasis en el trabajo como práctica de socialización. La gestión del dinero, por ejemplo, está asumida mucho más 
tarde por los adolescentes. Algunos casos de este tipo se encontraron, como el de Gino, un adolescente de 12 años que exigía por ejemplo un pago para actividades de pastoreo por su abuelo y su padre o la ayuda en un negocio de la madre. Ese parecía como una excepción y como un resultado de un actitud «moderna» en contraste con las prácticas que los informantes definían como «tradicionales». A pesar de la dimensión económica, Gino concluyó la descripción de sus variadas actividades económicas indicando: «[En realidad] estoy viendo un poco más [el trabajo] que la gente hace...» subrayando así la dimensión de socialización.

El siguiente esquema (fig. 2) fue desarrollado a manera de presentar estas cuatro dimensiones. Es necesario ver este modelo de forma sistémica donde cada dimensión influencia a la otra.

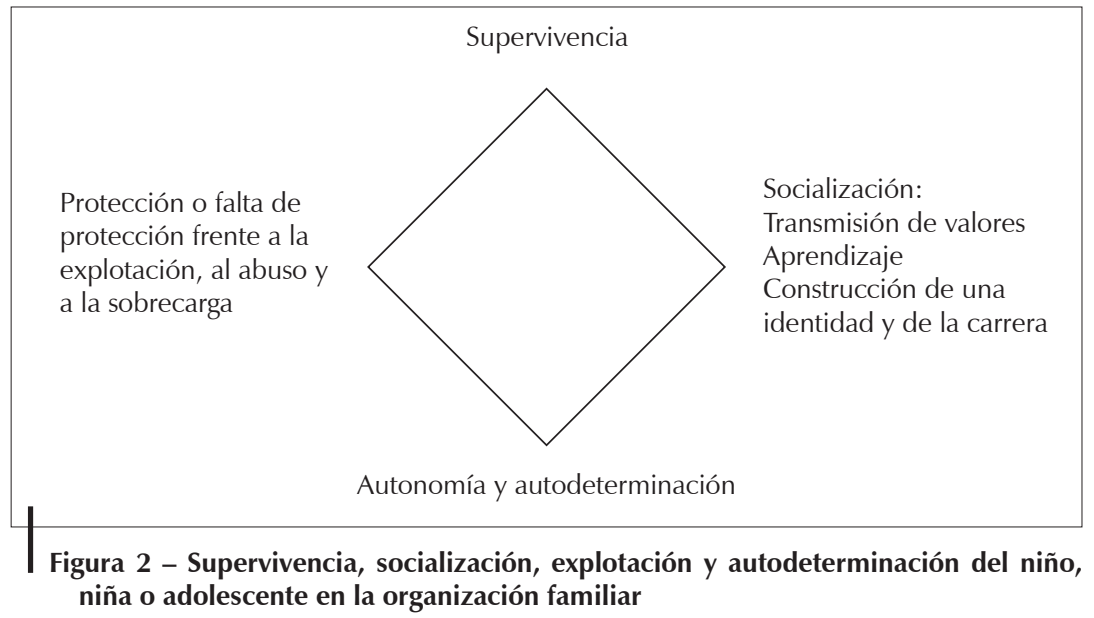

Desde el punto de vista teórico, más trabajos deberían ser desarrollados para experimentar este modelo. A pesar de ello, este permite entender cómo, para los niños y adultos, el trabajo perjudicial (así como el trabajo positivo) puede ser definido como un balance de ventajas y desventajas, una conceptualización ya propuesta por McKechnie \& Hobbes (1998). El esquema sugiere que las ventajas y desventajas son de naturaleza variable y los logros en términos de socialización, protección, supervivencia y autonomía pueden justificar la realización de una actividad que conlleva riesgos, desventajas o explotación. Solamente en el diálogo y tomando en cuenta las diferentes realidades sociales, culturales y económicas se pueden identificar las ventajas y desventajas asociadas al trabajo de los niños y las niñas. Las ventajas en términos de autodeterminación, socialización, protección, o supervivencia representan recursos importantes para la implementación de programas y políticas sociales capaces de apoyar a los niños y niñas en contextos de vida difíciles. 


\section{LA SOCIALIZACIÓN Y LA CARRERA DEL NIÑO TRABAJADOR}

Varios aspectos relacionados a la supervivencia han sido presentados en relación con los valores y prácticas de las familias donde la autonomía del niño no corresponde necesariamente a negligencia, si no a una visión particular de la infancia y de las competencias que el niño puede y tiene que adquirir. Hay que subrayar también las competencias necesarias para la venta en las calles y la importancia de las redes de solidaridad y cooperación. Estos aspectos se vinculan con la socialización del niño trabajador. Esta se define como un proceso en el cual el niño es activo y en parte aprende por la experiencia. En eso, la socialización se diferencia de la educación, centrada en el rol de los adultos que «enseñan».

En términos de socialización, el trabajo en la calle permite, por ejemplo:

- Aprender una o más actividades económicas,

- Aprender a conocer un espacio social con sus reglas, fuentes de soportes y peligros,

- Aprender a tomar responsabilidades frente a la familia, en la gestión del dinero y de los recursos,

- Aprender profesiones y actividades económicas que no existen en el barrio donde el niño vive.

El trabajo permite desarrollar competencias alternativas a los conocimientos escolares que son pertinentes en caso de crisis económica o problemas familiares y representan una formación profesional de facto para muchos adolescentes. Entre estos elementos se destaca la capacidad de ser activo a pesar de una situación económica difícil. Eso es un recurso importante para contraponer el sentimiento de impotencia que la pobreza puede generar. Cualquier observador que intente imaginar un escenario donde el niño o la niña se quedan a la espera de adultos para la satisfacción de sus necesidades se da cuenta que tal proceso sería, en contexto de precariedad y de pobreza, una fuente de frustración e impotencia. Al contrario, la capacidad de modificar el ambiente que lo rodea como tal es una fuente de autoestima e identidad positiva (Invernizzi, 2007).

El largo proceso de socialización no se puede observar en una investigación. A pesar de ello, algunos cambios en la identidad del niño o la niña sí se pueden identificar en un periodo de tres o cuatro años, como fue el caso del estudio en Lima. La noción de carrera aplicada por Riccardo Lucchini (1993) a la situación del niño que vive en la calle resultó muy útil. En la medida en que algunos niños fueron encontrados en un periodo de cuatro años, el material etnográfico permitió analizar cómo las experiencias que estos tienen del trabajo en la calle evolucionan en el tiempo. Como lo indica Lucchini, tales evoluciones solamente pueden intervenir gracias a las competencias que el niño va ganando. La carrera fue resumida en cinco etapas. Así como los modelos de organización familiar presentados anteriormente, las etapas son tipos ideales que no se encuentran en las historias de todos los niños. En otras palabras, no todos los niños pasan por 
estas etapas al mismo tiempo, otros dejan la calle temprano y algunos se quedan por mucho tiempo en una u otra.

\section{1. El inicio del trabajo en la calle}

Los niños empiezan a trabajar en la calle en condiciones diferentes. Esto puede ocurrir de forma progresiva o repentina. El peso de las dificultades económicas, de una crisis familiar o de la enfermedad de un adulto puede crear una situación en la que el niño o la niña tiende a salir — de un día para otro - a trabajar en la calle para generar dinero de manera urgente (véase también Cavagnoud, 2012). Paradójicamente, esta forma precipitada de comenzar a trabajar ocurre más frecuentemente en familias donde los padres excluyen la idea de que el niño puede trabajar. El trabajo es visto entonces como una estrategia de supervivencia que es tolerada en momentos de crisis. En estas situaciones, acontece que el niño está enviado solo a la calle, sin experiencia, preparación ni supervisión, debiendo así enfrentar desafíos muy importantes. El relato de Marco, adulto al momento de la entrevista, describe la situación acontecida durante la separación de sus padres:

Súbitamente, me vi presionado por mi madre para que salga a trabajar. Mi madre [...] empezó a preparar cakes y me mandó a venderlos a la calle. [...] me mandó a mí, ella dijo que no podía salir a trabajar a la calle porque era blanca, y mi hermana tampoco por la misma razón. Empecé a vender los cakes... [...] Caminaba y ofrecía. [...] Ella no sabía nada de cómo vendía, nunca había vendido nada. Ella me dijo que vaya donde el placero [...]. Es una palabra muy antigua: el placero es el serrano que vende en la plaza. Entonces me dijo que vaya a vender. Cuando le pregunté por qué no podía ir con mi hermana, ella me dijo: «porque es blanca». Entonces como que no me sentía muy estimulado para ir a trabajar...

Otra modalidad es la de un inicio progresivo. Muchos niños empiezan a trabajar en la etapa 3. Aquí, las presiones económicas son menos significativas y muchas veces el niño goza de cierta preparación o está acompañado de adultos u otros niños y adolescentes. Muchas veces, esta experiencia se presenta como una decisión del niño y se acompaña de juegos y de una exploración a pesar que el niño contribuye a la economía del hogar. En este tipo de experiencia, el niño parece trasladarse a la etapa 3 sin conocer el trabajo-subsistencia que forma parte de la experiencia del niño o la niña que comienza a trabajar de forma precipitada.

\section{2. El trabajo-subsistencia}

El trabajo-subsistencia se caracteriza por una visión de la venta en la calle como un medio para la subsistencia y como una tarea que no se puede evitar. Por supuesto, la subsistencia siempre entra en consideración en las actividades económicas de la calle. En otras etapas de la carrera, esta puede articularse con otros intereses y actividades, como el juego y la exploración. Al contrario, 
las modalidades de trabajo en este caso no dejan ningún espacio para otras dimensiones. Aprender a trabajar es una prioridad. Niños y adultos expresan la falta de competencia de uno u otro niño que «no sabe vender» o que «tiene vergüenza» pues no sabe cómo ofrecer productos o comunicarse con los clientes. El «mejor trabajo» para los niños es lo que da más dinero y lo que cuesta menos esfuerzo. La naturaleza útil de lo que el niño hace no es muy importante y la venta se desarrolla a veces de forma muy cercana a la mendicidad. Si esa es la situación de Marco al empezar el trabajo de venta de cakes, su relato muestra que él se va a mover a un trabajo lúdico, en búsqueda de una exploración de la ciudad, y, rápidamente, a un trabajo-identidad.

\section{3. El trabajo lúdico}

Para los niños que empezaron a trabajar de forma precipitada y con obligaciones económicas importantes, el juego parece intervenir después de la etapa 2 y cuando ya tienen suficientes competencias en la calle para asegurar cierto rendimiento, cierta productividad y tener un control relativo sobre el mundo de la calle. Como se mencionó, algunos niños empiezan el trabajo de forma lúdica. Eso es posible porque el niño o la niña tiene suficientes competencias y autonomía, una productividad suficiente así como pedidos de los padres que no son excesivos. Algunos niños que empezaron a trabajar en la calle de esa forma lo hicieron cerca del lugar de venta del padre u otro familiar. Esta forma de trabajo se caracteriza por una constante búsqueda de diversión, de exploración así como de actividades para compartir con los amigos. Así, el trabajo con un amigo es más valorado. Un niño lustrabotas comenta al respeto:

Mi primo [...] ese tiempo no lustraba todavía, no lustraba. Yo le he dicho. Como yo me sentía solo ino? También no me llevaba mucho con los que lustraban...

El buen trabajo, desde el punto de vista del niño, es aquel que permite conciliar el juego y la exploración y que se realiza con los amigos, lo que muchas veces genera conflictos con los adultos. El niño que se sitúa en esa etapa sabe diferenciar las actividades que son inútiles desde el punto de vista del cliente. La venta se presenta como una oferta relajada de productos y el pedido insistente o la postura de sumisión que caracterizan la mendicidad ya están ausentes. Las palabras de Lili son significativas de esta forma de pensar el trabajo: «[Antes de venir aquí] yo no pensaba que en la escuela, y no a divertirme...!». A pesar de que Lili lleva cada día dinero a su familia y que su contribución es importante para la subsistencia, ella ve el trabajo principalmente como una actividad lúdica.

\section{4. El trabajo-identidad}

En esa etapa de la carrera, la búsqueda de un reconocimiento positivo y de un estatus es predominante. El trabajo se vuelve, para el niño, un atributo de su 
identidad. Por cierto, el niño juega y explora pero esto no es más lo que caracteriza el «buen trabajo». Eso se define más bien a través de las competencias que puede exhibir así como el estatus que él o ella quiere adquirir. El caso de Elena, de 18 años, que relata sus experiencias de niña trabajadora, demuestra la complejidad de las acciones de los niños:

... Y mi papá tenía otro compromiso, ya con esta señora no, y entonces también así, no, dejaba la plata así, pero no tanto como antes, como primero se preocupaba... Allí [dije]: «iyo voy a comenzar a vender! Después voy a comprar cualquier cosa para comer... para darle a mi mamá». Y me puse a vender, pues, a vender de caja no más, la primera vez. Y estaba vendiendo, (se ríe) y nadie me compraba: «qué hago, qué hago?». «Cómpreme, vecina le voy a dar barato», [le dije] a mi vecina. «iPobrecita, mi hijita, a mediodía te voy a comprar todo!». «Tú no me compres, ya tienen, tienes para la venta» dije. Y me agarré mis productos, y me fui al mercado de acá. Agarré, me senté y me puse a vender, iy vendí mi verdura! Y después ya tenía un pequeño fondito, ¿no? Entonces agarré, yo lo tenía guardado. Y a veces mi papá me daba cincuenta céntimos. No es que me daba mucha propina, sino para comprar un caramelo. Yo me lo guardaba... iDe allí me fui a la Parada!... [se ríe].

Lo que Elena describe es la necesidad de comprobar sus propias competencias y la capacidad de tener un negocio de forma autónoma. El reconocimiento de un trabajo útil y digno es central. Puede ser que el niño realice un trabajo poco rentable o útil o pida ayuda pero más bien eso está visto de forma negativa. En ese sentido, su visión del trabajo se acerca a la de los adultos. En las organizaciones familiares que no promueven autonomía y reconocimiento las relaciones pueden tornarse más problemáticas.

\section{5. La salida de la calle}

La investigación permitió aprender muy poco sobre la salida de la calle. Los adolescentes con las actividades más precarias eran también los que lo más rápido intentaban salir de la calle. Para los que trabajaban con familiares o cerca de ellos en un puesto fijo, la situación era diferente y la multiplicación de los puestos de venta era una manera de seguir una carrera en la calle, a veces hasta la edad adulta. Empleos en pequeños negocios era también un tipo de salida. Mejores conocimientos sobre las trayectorias de los niños y adolescentes trabajadores serían útiles para las intervenciones y las políticas sociales. De forma más general, son las prácticas de socialización a través del trabajo, en contextos económicos difíciles, que deberían ser estudiadas más detalladamente. Como lo ha demostrado por ejemplo Schlemmer (2007), un discurso simplificador sobre el trabajo infantil opuesto a la escolarización no permite capturar la complejidad de las situaciones concretas. 


\section{CONCLUSIONES}

El trabajo en la calle de los niños, niñas y adolescentes no es el resultado inevitable de pobreza y no se explica simplemente por condiciones económicas difíciles. El argumento de este texto es que un conjunto de miradas es necesario pare enfocar una realidad compleja de tal forma que se pueda apoyar a niños, niñas, padres y comunidades de forma eficaz. Esto exige pensar simultáneamente en los aspectos económicos, sociales, culturales y de identidad. También exige conceptualizar los intereses de los adultos y los de los niños y niñas, así como la evolución de su situación en el tiempo. La cuestión de género, aplicada a las niñas así como a las madres, también parece importante. El trabajo no es una fuente de estima para todos los niños trabajadores ni tampoco una fuente de autonomía para todos ellos. Incluye a veces aspectos de explotación y abuso. A pesar de ello, la acción no puede limitarse a luchar contra el abuso y la explotación sino que se tiene que considerar también otras dimensiones tales como la supervivencia de la familia, la socialización y la autonomía y autodeterminación de niños y adolescentes.

El trabajo con las comunidades exige tomar en cuenta su forma de pensar sobre la infancia y el trabajo, sus redes de soporte y las competencias que existen. Resulta importante identificar, valorar y sostener los esfuerzos, en la vida cotidiana, que los niños y las niñas, los adolescentes y los adultos hacen para enfrentar problemas y dificultades en contextos precarios. Para toda intervención enfocada en los derechos humanos de los niños y niñas así como de los adultos alrededor de ellos, eso se traslada en el principio de respeto de la dignidad de todos los miembros de la comunidad, adultos y niños que la conceptualización de las prácticas cotidianas quiere apoyar. Los contextos sociales, económicos y culturales en que estas comunidades se encuentran varían mucho de una sociedad a otra. La referencia a los estudios en Grecia y Portugal muestra la necesidad así como la posibilidad de construir un cuadro teórico suficientemente extendido para tomar en cuenta la diversidad de contextos de vida de los niños y adolescentes trabajadores.

\section{Referencias citadas}

ALARCÓN, W., 1991 - Entre calles y plazas: el trabajo de los niños en Lima, 179 pp.; Lima: Instituto de Estudios Peruanos, Unicef, Asociación laboral para el desarrollo.

BOURDIEU, P., 1992 - Réponses. Pour une anthropologie réflexive, 267 pp., París: Seuil.

CAVAGNOUD, R., 2012 - L'enfance entre école et travail au Pérou. Enquête sur des adolescents à Lima, 247 pp., París: Karthala.

CANTWELL, N., 2011 - Are Children's Rights still Human? In: The Human Rights of Children. From Visions to Implementation (A. Invernizzi \& J. Williams, eds.): 37-59; Farhnam, Burlington: Ashgate. 
Niños y adolescentes trabajadores en Lima: vida cotidiana y estrategias familiares de supervivencia

ENNEW, J., 1986 - Mujercita y mamacita: girls growing up in Lima. Bulletin of American Research, 5 (2): 49-66.

FULLER, N., 1997 - Identidades masculinas: varones de clase media en el Perú, 192 pp.; Lima: Pontificia Universidad Católica del Perú.

INVERNIZZI, A., 2001 - La vie quotidienne des enfants travailleurs. Stratégies de survie et socialisation dans les rues de Lima, 286 pp., París: L'Harmattan.

INVERNIZZI, A., 2003a - Street-working children and adolescents in Lima: work as an agent of socialization. Childhood, 10 (3): 319-341.

INVERNIZZI, A., 2003b - Des enfants libérés de l'exploitation ou des enfants travailleurs doublement opprimés ? Positions et oppositions sur le travail des enfants. Déviance et Société, 27 (4): 459-548.

INVERNIZZI, A., 2005 - Perspectives on children's work in the Algarve (Portugal) and their implication for social policy. Critical Social Policy, 25 (2): 198-222.

INVERNIZZI, A., 2007 - Enfants travailleurs au Pérou et au Portugal: diversité des expériences, acquisition de savoirs et savoir faire. Cahiers de la recherche sur l'éducation et les savoirs, 6: 171-190.

INVERNIZZI, A., 2011 - Vulnerability to exploitation and trafficking of Bulgarian children and adolescents in Greece. A case study of street based survival strategies in Thessaloniki. Research Report. Project MARIO in collaboration with ARSIS, Budapest.

INVERNIZZI, A. \& TOMÉ, S., 2007 - O Trabalho dos adolescentes no Algarve: um estudo sobre as suas motivações, organizações familiares e práticas de socialização. Análise Social, XLII (3): 875-898.

JAMES, A. \& PROUT, A., 1990 - Constructing and Reconstructing Childhood: Contemporary Issues in the Sociological Study of Childhood, 280 pp.; Londres: Falmer Press.

LOBO, S., 1984 - Tengo casa propia: organización social en las barriadas de Lima, 283 pp.; Lima: Instituto de Estudios Peruanos, Instituto indigenista interamericano.

LUCCHINI, R., 1993 - Enfant de la rue. Identité, sociabilité, drogue, 248 pp.; París, Ginebra: Droz.

LUCCHINI, R., 1996 - Sociologie de la survie. L'enfant dans la rue, 323 pp.; París: Presses Universitaires de France.

LUCCHINI, R., 1998 - Sociología de la supervivencia: el niño y la calle, 203 pp.; Iztacala: Universidad Nacional autónoma de México.

McKECHNIE, J. \& HOBBS, S., 1998 - Working Children: Reconsidering the Debates, 87 pp.; Amsterdam: International Working Group on Child Labour.

ORTIZ RASCANIERE, A., 1994 - Un estudio sobre los grupos autónomos de niños a partir de un trabajo de campo en Champacocccha, Andahuaylas; Lima: Ministerio de Educación, Fundación Bernard Van Leer.

PORTUGAL CATACORA, J., 1988 - El niño indígena, 373 pp.; Lima: Artex.

RUIZ BRAVO, P. (ed.), 1996 - Detrás de la puerta: Hombres y mujeres en el Perú de hoy, 310 pp.; Lima: Pontificia Universidad Católica del Perú.

SCHLEMMER, B., 2007 - Working Children in Fez (Morocco). Relationship between Knowledge and Strategies for Social and Professional Integration. In: Working to be someone. Theoretical approaches and international empirical reports on working children (B. Hungerland, M. Liebel, B. Milne \& A. Wihstutz, eds.): 135-144; Londres: Jessica Kingsley.

WEBER, M., 1982 - L'objectivité de la connaissance dans les sciences et la politique sociales. In: La sociologie. Textes essentiels (K. M. Van Meter, ed.): 332-333; París: Larousse. 